\title{
Investigating diesel engines as an atmospheric source of isocyanic acid in urban areas
}

\author{
Shantanu H. Jathar ${ }^{1}$, Christopher Heppding ${ }^{1}$, Michael F. Link ${ }^{2}$, Delphine K. Farmer ${ }^{2}$, Ali Akherati ${ }^{1}$, \\ Michael J. Kleeman ${ }^{3}$, Joost A. de Gouw ${ }^{4,5}$, Patrick R. Veres ${ }^{4,5}$, and James M. Roberts ${ }^{4}$ \\ ${ }^{1}$ Department of Mechanical Engineering, Colorado State University, Fort Collins, CO 80523, USA \\ ${ }^{2}$ Department of Chemistry, Colorado State University, Fort Collins, CO 80523, USA \\ ${ }^{3}$ Department of Civil and Environmental Engineering, University of California Davis, Davis, CA 95616, USA \\ ${ }^{4}$ NOAA Earth System Research Laboratory, Chemical Sciences Division, Boulder, CO 80305, USA \\ ${ }^{5}$ Cooperative Institute for Research in Environmental Sciences, University of Colorado, Boulder, CO 80305, USA \\ Correspondence to: Shantanu H. Jathar (shantanu.jathar@colostate.edu)
}

Received: 20 January 2017 - Discussion started: 22 February 2017

Revised: 18 May 2017 - Accepted: 19 May 2017 - Published: 26 July 2017

\begin{abstract}
Isocyanic acid (HNCO), an acidic gas found in tobacco smoke, urban environments, and biomass-burningaffected regions, has been linked to adverse health outcomes. Gasoline- and diesel-powered engines and biomass burning are known to emit HNCO and hypothesized to emit precursors such as amides that can photochemically react to produce HNCO in the atmosphere. Increasingly, diesel engines in developed countries like the United States are required to use selective catalytic reduction (SCR) systems to reduce tailpipe emissions of oxides of nitrogen. SCR chemistry is known to produce $\mathrm{HNCO}$ as an intermediate product, and SCR systems have been implicated as an atmospheric source of HNCO. In this work, we measure HNCO emissions from an SCR system-equipped diesel engine and, in combination with earlier data, use a three-dimensional chemical transport model (CTM) to simulate the ambient concentrations and source/pathway contributions to $\mathrm{HNCO}$ in an urban environment. Engine tests were conducted at three different engine loads, using two different fuels and at multiple operating points. HNCO was measured using an acetate chemical ionization mass spectrometer. The diesel engine was found to emit primary HNCO (3-90 $\mathrm{mg} \mathrm{kg} \mathrm{fuel}^{-1}$ ) but we did not find any evidence that the SCR system or other aftertreatment devices (i.e., oxidation catalyst and particle filter) produced or enhanced HNCO emissions. The CTM predictions compared well with the only available observational datasets for HNCO in urban areas but underpredicted the contribution from secondary processes. The comparison
\end{abstract}

implied that diesel-powered engines were the largest source of HNCO in urban areas. The CTM also predicted that dailyaveraged concentrations of HNCO reached a maximum of $\sim 110$ pptv but were an order of magnitude lower than the 1 ppbv level that could be associated with physiological effects in humans. Precursor contributions from other combustion sources (gasoline and biomass burning) and wintertime conditions could enhance HNCO concentrations but need to be explored in future work.

\section{Introduction}

Isocyanic acid (HNCO) is a mildly acidic gas, which is highly soluble at physiologic $\mathrm{pH}$ and can participate in carbamylation reactions in the human body (Wang et al., 2007) and lead to adverse health outcomes such as cataracts, atherosclerosis, and rheumatoid arthritis (Fullerton et al., 2008; Scott et al., 2010). Isocyanates, the family to which HNCO belongs, are extremely hazardous. The accidental release of methyl isocyanate from a pesticide plant in Bhopal, India, in 1984 resulted in thousands of deaths and hundreds of thousands in injuries within weeks of the release (Broughton, 2005). Although isocyanates are understood to be toxic and regulated through best practices in indoor and occupational environments (Alexeeff et al., 2000; SWEA, 2005), it is unclear whether ambient concentrations of HNCO (and isocyanates in general) are high enough for 
it be of concern as an outdoor air pollutant. Roberts et al. (2011) proposed that exposure to HNCO concentrations exceeding $1 \mathrm{ppbv}$ could be harmful to humans.

Only a few studies have measured ambient concentrations of HNCO. Roberts and coworkers (Roberts et al., 2011, 2014) used a chemical ionization mass spectrometer (CIMS) to measure HNCO in urban areas (Pasadena, CA) and biomass-burning-affected regions (suburban and rural Colorado). While concentrations in urban areas were consistently below 100 pptv, ambient HNCO concentrations exceeded $100 \mathrm{pptv}$ in regions affected by wildfire plumes and agricultural burning; in case of the later source, HNCO concentrations reached as high as $1.2 \mathrm{ppbv}$. In urban areas, they found evidence that $60 \%$ of the HNCO came from primary (i.e., directly emitted) sources while $40 \%$ came from secondary (i.e., photochemically produced) sources. Wentzell et al. (2013) used a CIMS to measure ambient concentrations of $\mathrm{HNCO}$ in urban Toronto and found that the measured HNCO (20-140 pptv) correlated strongly with benzene, which the authors interpreted as a fossil-fuel-based source. Zhao et al. (2014) measured HNCO using a CIMS at an elevated site near La Jolla, CA, and found evidence for photochemical production as well as significant uptake of HNCO by clouds. And finally, Chandra and Sinha (2016) measured ambient HNCO in Mohali, India, using a proton transfer reaction mass spectrometer (PTR-MS) and found that the ambient concentrations regularly exceeded $1 \mathrm{ppbv}$ during postharvest agricultural burning. Despite only a handful of observations in a few locations, it is clear that atmospheric $\mathrm{HNCO}$ has both natural (e.g., wildfires) and anthropogenic (e.g., agricultural burning) sources. With these sparse observations, we are just beginning to understand the spatiotemporal distribution and the contribution of natural and anthropogenic sources to ambient concentrations of HNCO.

Similar to the ambient observations, there have only been a handful of studies that have investigated HNCO emissions from anthropogenic sources, most of which have focused on gasoline- and diesel-powered sources. Previous HNCO studies on natural, biomass burning sources have been performed by Roberts et al. (2011) and Coggon et al. (2016). Brady et al. (2014) measured tailpipe emissions of HNCO from eight light-duty gasoline vehicles (LDGVs) and suggested that HNCO emissions from LDGVs were not a result of incylinder combustion but rather a result of $\mathrm{CO}-$ and $\mathrm{NO}_{x}$ dependent chemistry in the aftertreatment device, namely the three-way catalytic converter. Wentzell et al. (2013) measured tailpipe emissions of HNCO from an on-road diesel engine but did not conclusively point to the source (incylinder or aftertreatment) of the HNCO. The HNCO emissions were comparable to those from LDGVs measured by Brady et al. (2014) but varied substantially (order of magnitude or more) with the drive cycle and possibly with the coemitted $\mathrm{NO}_{x}$ emissions. Suarez-Bertoa and Astorga (2016) have measured tailpipe emissions of HNCO from a suite of modern on-road gasoline and diesel vehicles and found that the gasoline vehicles and newer diesel vehicles produced more HNCO than modern-day diesel vehicles. Link et al. (2016) found that diesel engines could not only produce in-cylinder $\mathrm{HNCO}$ but also emit precursors (e.g., amides) that could photooxidize in the atmosphere to form secondary HNCO. It appears that there are large uncertainties surrounding the sources and precursors of $\mathrm{HNCO}$ from anthropogenic sources (e.g., in-cylinder or aftertreatment, primary or secondary) and there is a need to perform additional studies that can help elucidate the chemistry and conditions that lead to HNCO production.

Increasingly, new diesel engines sold in developed economies (e.g., United States, Canada, European Union) need to be equipped with selective catalytic reduction (SCR) systems to reduce tailpipe emissions of $\mathrm{NO}_{x}$ and meet newer/stricter emission standards (e.g., EPA's 2010 standard for heavy-duty on-road engines, California's Drayage Truck Regulation, EPA's Tier 4 standard for non-road engines, Euro 6 standard for heavy-duty trucks and buses). In an SCR system, urea thermally decomposes to produce ammonia $\left(\mathrm{NH}_{3}\right)$ and $\mathrm{HNCO}$ :

$\mathrm{H}_{2} \mathrm{~N}-\mathrm{CO}-\mathrm{NH}_{2} \rightarrow \mathrm{NH}_{3}+\mathrm{HNCO}$.

The HNCO rapidly hydrolyzes on the catalyst surface to yield another $\mathrm{NH}_{3}$ molecule:

$\mathrm{HNCO}+\mathrm{H}_{2} \mathrm{O} \rightarrow \mathrm{NH}_{3}+\mathrm{CO}_{2}$.

$\mathrm{NH}_{3}$ is the active agent that reduces $\mathrm{NO}$ and $\mathrm{NO}_{2}$ to $\mathrm{N}_{2}$ and $\mathrm{H}_{2} \mathrm{O}$ :

$2 \mathrm{NH}_{3}+\mathrm{NO}+\mathrm{NO}_{2} \rightarrow 2 \mathrm{~N}_{2}+3 \mathrm{H}_{2} \mathrm{O}$,
$4 \mathrm{NH}_{3}+4 \mathrm{NO}+\mathrm{O}_{2} \rightarrow 4 \mathrm{~N}_{2}+6 \mathrm{H}_{2} \mathrm{O}$
$8 \mathrm{NH}_{3}+6 \mathrm{NO}_{2} \rightarrow 7 \mathrm{~N}_{2}+12 \mathrm{H}_{2} \mathrm{O}$.

Since SCR systems produce HNCO as an intermediate product, they have been implicated as an atmospheric source of HNCO (Roberts et al., 2011). Heeb et al. (Heeb et al., 2011, 2012) performed experiments on an on-road diesel engine and found an order-of-magnitude increase in HNCO emissions with the SCR system engaged, implying that SCR systems could potentially be a source for HNCO. However, Heeb et al. (Heeb et al., 2011, 2012) used an offline technique to measure HNCO, which lacks the time resolution and sensitivity found in online mass spectrometry instrumentation.

To date, there has only been a single study that has used a large-scale model to simulate ambient concentrations of HNCO from biomass burning and biofuel combustion. Leveraging the measurements of Roberts et al. (2011), Young et al. (2012) simulated ambient concentrations of HNCO using a global model. They found that surface $\mathrm{HNCO}$ concentrations might only be of human health concern ( $>1 \mathrm{ppbv}$ for more than 7 days of the year) in tropical regions dominated by biomass burning (Southeast Asia) and in developing countries (northern India and eastern China) dominated by 
biofuel combustion. Although Young et al. (2012) acknowledged that anthropogenic sources such as gasoline and diesel engines and secondary processes in the atmosphere might be important contributors to atmospheric HNCO, they did not include these sources/pathways in their study. Furthermore, the grid resolution of the model used by Young et al. (2012) was too coarse $\left(2.8^{\circ} \times 2.8^{\circ}\right)$ to resolve elevated HNCO concentrations in urban areas. So it is not known whether anthropogenic sources other than biofuel combustion and secondary production could result in elevated levels of $\mathrm{HNCO}$ in urban areas affected by mobile source pollution.

In this work, we performed laboratory experiments to measure HNCO emissions from an SCR-equipped, modern-day, non-road diesel engine to test whether SCR systems were a potential source of $\mathrm{HNCO}$. To quantify $\mathrm{HNCO}$ emissions under different operating conditions, we performed these tests under varying urea injection rates (stoichiometric ratios of 0 to $\sim 1.3$ ), engine loads (idle-like, intermediate speed, rated speed), and fuels (diesel, biodiesel). The HNCO was measured using a time-of-flight, acetate-based, chemical ionization mass spectrometer. Based on findings from our and previous work, we used a chemical transport model (CTM) to simulate ground-level concentrations and source (gasoline, diesel, biomass burning) and process (primary, secondary) contributions to $\mathrm{HNCO}$ in California.

\section{Methods}

\subsection{Laboratory experiments}

The HNCO experiments were conducted on an engine dynamometer-mounted (Midwest Inductor Dynamometer 1014A) 4-cylinder, turbocharged and intercooled, 4.5 L, $175 \mathrm{hp}$, John Deere 4045 PowerTech Plus diesel engine; this engine platform has been part of several earlier research studies (Jathar et al., 2017; Drenth et al., 2014). The engine consisted of a variable geometry turbocharger, exhaust-gas recirculation, and electronically controlled high-pressure common rail fuel injection and met non-road Tier 3 emission standards. A diesel oxidation catalyst (DOC, John Deere RE568883) and diesel particulate filter (DPF, John Deere RE567056) were retrofitted on the exhaust system to meet non-road interim Tier 4 emission standards. Recently, Jathar et al. (2017) found that the DOC + DPF retrofitted system used in this work at $50 \%$ engine load resulted in reductions of $\mathrm{CO}$ and particulate matter similar to those found across a compendium of on- and non-road diesel engines (May et al., 2014).

We built and installed a custom SCR system in the exhaust line that allowed us to control and explore $\mathrm{HNCO}$ emissions as a function of varying urea injection rates; the SCR system was installed downstream of the DOC + DPF (see schematic in Fig. S1 in the Supplement). The urea injection rates were controlled using an SCR-specific engine control unit (ECU) provided by John Deere. The SCR ECU controlled a high-pressure pump coupled to an injector to aerosolize urea into the exhaust. A baffle-based mixer downstream of the injection location facilitated homogenous mixing of the aerosolized urea with exhaust. The urea and exhaust mixture was passed over $0.014 \mathrm{~m}^{3}$ of $\mathrm{Cu}$-zeolite catalyst, which are catalysts of choice for on-road SCR systems in the United States. The total catalyst volume for our system $\left(0.014 \mathrm{~m}^{3}\right)$ was determined based on recommended values for the space velocity, which quantifies the exhaust volume processed per hour.

We performed a total of nine engine tests at three different engine loads (idle-like, $50 \%$ load at intermittent speed, and $50 \%$ load at rated speed) and with two different fuels (diesel and fatty acid methyl ester-based biodiesel). The three engine loads were (i) $45 \mathrm{Nm}$ at $2400 \mathrm{RPM}$ and $11 \mathrm{~kW}$, (ii) $284 \mathrm{Nm}$ at $1500 \mathrm{RPM}$ and $45 \mathrm{~kW}$, and (iii) $226 \mathrm{Nm}$ at $2400 \mathrm{RPM}$ and $57 \mathrm{~kW}$, which corresponded to modes 4,7 , and 3 on the ISO 8178-4 C1 duty cycle, respectively. The ISO 8178 duty cycle is an international standard used for emission certification for non-road diesel engines. The diesel fuel was commercial, non-road, ultra-low-sulfur diesel (ULSD) and sourced locally while the biodiesel fuel (B100) was sourced from AG Processing Inc. (Sergeant Bluff, IA) and produced from soy; we have included the fuel certificate in the Supplement. Each test included a sweep across three to four urea injection rates for each engine load-fuel combination. We used commonly available diesel exhaust fluid - a $32.5: 67.5$ mixture of urea and water - as our urea source. After changing the urea injection rate, engine load, or fuel, the emissions were allowed to stabilize for approximately $10 \mathrm{~min}$ before values were recorded.

Raw exhaust was transferred to a Siemens five-gas analyzer using a $110^{\circ} \mathrm{C}$ heated Teflon ${ }^{\mathrm{TM}}$ transfer line followed by a water trap to measure $\mathrm{CO}_{2}$ (non-dispersive infrared), $\mathrm{CO}$ (non-dispersive infrared), unburned hydrocarbons (flame ionization detector), $\mathrm{NO}$ and $\mathrm{NO}_{y}$ (chemiluminescence), and $\mathrm{O}_{2}$ (electrochemical). Raw exhaust was sampled through an isokinetic probe using 15 feet of Silcosteel ${ }^{\circledR}$ tubing heated to $150{ }^{\circ} \mathrm{C}$ and diluted with activated charcoal- and HEPAfiltered air using a Hildemann-style dilution sampler (Hildemann et al., 1989). The dilution ratios were calculated using the method outlined by Lipsky and Robinson (2006) based on $\mathrm{CO}_{2}$ measurements. The diluted exhaust was diluted even further with ultra-high-purity $\mathrm{N}_{2}$ before being sampled by an acetate reagent ion-based time-of-flight chemical ionization mass spectrometer (ToF-CIMS; Tofwerk AG and Aerodyne Research, Inc.) to measure HNCO. The operation of the CIMS and reagent ion chemistry was similar to that described in Link et al. (2016) with minor differences. The acetic anhydride reagent source was stored in an oven and transfer lines were kept at a constant temperature of $40{ }^{\circ} \mathrm{C}$ using heating tape. The ToF duty cycle was set to $16 \mathrm{kHz}$ and data were acquired at $1 \mathrm{~Hz}$ resolution. A cross-calibration method was used to quantify HNCO similar to that described 
in Brady et al. (2014). The primary assumption of the crosscalibration method was that the ratio of formic acid sensitivity to HNCO sensitivity would remain the same between the two instruments operated under similar voltage settings as described in Eq. (1):

$[\mathrm{HNCO}]_{\mathrm{pptv}}=\frac{\left[\mathrm{CNO}^{-}\right]_{(2)} F_{\text {formic (1) }}}{F_{\text {formic (2) }} F_{\mathrm{HNCO}(1)}}$,

where $\left[\mathrm{CNO}^{-}\right]_{(2)}$ is the measured $\mathrm{CNO}^{-}$ion signal normalized to the acetate reagent ion signal, $F_{\text {formic(1) }}$ is the formic acid sensitivity (ncps pptv ${ }^{-1}$ ) measured by Link et al. (2016), $F_{\text {formic(2) }}$ is the formic acid sensitivity $\left(\right.$ ncps pptv $\left.{ }^{-1}\right)$ measured during this study, and $F_{\mathrm{HNCO}(1)}$ is the HNCO sensitivity (ncps pptv ${ }^{-1}$ ) as reported in Link et al. (2016). A formic acid calibration was performed at the beginning and end of each day of experiments to obtain $F_{\text {formic(2) }}$ using a custom built permeation oven and formic acid permeation source.

Background-corrected emission factors $(\mathrm{EF})$ for $\mathrm{CO}, \mathrm{NO}$, $\mathrm{NO}_{2}$, and $\mathrm{HNCO}$ were calculated using Eq. 2 and expressed as grams of pollutant produced per $\mathrm{kg}$ of fuel burned. Since more than $98 \%$ of the fuel carbon was emitted as $\mathrm{CO}_{2}$, we assumed that in Eq. (2) all of the carbon in the fuel was converted to $\mathrm{CO}_{2}$.

$\mathrm{EF}=\frac{[P]}{\frac{\left[\mathrm{CO}_{2}\right]}{\mathrm{MW}_{\mathrm{CO}_{2}}}} \times \mathrm{MW}_{\mathrm{C}} \times C_{\mathrm{f}} \times F C$

Here, $[P]$ is the background corrected pollutant concentration in $\mu \mathrm{g} \mathrm{m}^{-3}$, $\left[\mathrm{CO}_{2}\right]$ is the background corrected $\mathrm{CO}_{2}$ concentration in $\mu \mathrm{g} \mathrm{m}^{-3}, \mathrm{MW}_{\mathrm{CO}_{2}}$ is the molecular weight for $\mathrm{CO}_{2}, \mathrm{MW}_{\mathrm{C}}$ is the atomic weight of $\mathrm{C}$, and $C_{\mathrm{f}}$ is the carbon mass fraction in the fuel in $\mathrm{kg} \mathrm{C} \mathrm{kg} \mathrm{fuel}{ }^{-1}$. We use a $C_{\mathrm{f}}$ of 0.85 for diesel and 0.77 for biodiesel (Gordon et al., 2014).

\subsection{Chemical transport modeling}

The UCD/CIT is a regional chemical transport model that has been extensively used to simulate the emissions, transport, chemistry, deposition and source contribution of pollutants in the lower troposphere (Kleeman and Cass, 2001) and evaluated against meteorological and gas- and particle-phase measurements (Hu et al., 2012, 2015; Jathar et al., 2015, 2016). HNCO simulations were performed for the state of California at a grid resolution of $24 \mathrm{~km}$ followed by a nested simulation over the South Coast Air Basin (SoCAB) domain at a grid resolution of $8 \mathrm{~km}$ from 15 July to 2 August 2005 . Simulations were performed for California since the state is home to the five most polluted cities in the United States for ozone and particulate matter (American Lung Association, 2016). We used the (i) CRPAQS (California Regional $\mathrm{PM}_{10} / \mathrm{PM}_{2.5}$ Air Quality Study) inventory for anthropogenic emissions, (ii) FINN (Fire Inventory for National Center for Atmospheric Research) inventory for biomass burning emissions (Wiedinmyer et al., 2011), and (iii) MEGAN (Model of Emissions of Gases and Aerosols from Nature) model for biogenic emissions (Guenther et al., 2006). Hourly meteorological fields were produced using the Weather Research and Forecasting (WRF) v3.4 model (http://www.wrf-model.org). Initial and hourly varying boundary conditions were based on the results from the global model MOZART-4/NCEP (Emmons et al., 2010). Gas-phase chemistry was modeled using SAPRC-11. For more details, we refer the reader to previous model applications (Hu et al., 2012; Jathar et al., 2016) and evaluations (Jathar et al., 2015, 2016).

Primary emissions of HNCO were calculated by first determining a source-specific $\mathrm{HNCO}$ : $\mathrm{CO}$ ratio (see Table 1) and then combining them with source-specific, spatiotemporally resolved $\mathrm{CO}$ emissions to build an inventory for $\mathrm{HNCO}$ emissions. We used a ratio-based approach rather than an emission-factor-based approach for the following reasons. First, to our knowledge, there were no available HNCO emission factors for biomass burning. Second, there was large variability in the measured $\mathrm{HNCO}$ emission factors for both gasoline and diesel engines across different studies (this is illustrated in Fig. 3 and discussed in Sect. 3.2), which presumably arose from differences in engine sizes and technology. And finally, only a handful of sources have been characterized for HNCO emissions in previous studies and, in our view, the data may not be representative enough to develop an HNCO inventory using emission factors and fuel activity data. For the same reason, we assumed equivalence between on- and non-road engine sources in developing a source-specific $\mathrm{HNCO}$ : $\mathrm{CO}$ ratio.

We considered three sources for primary emissions of HNCO: (1) on- and non-road diesel, (2) on- and non-road gasoline, and (3) biomass burning (includes residential wood combustion). HNCO : $\mathrm{CO}$ ratios for diesel sources were determined based on the range of measured $\mathrm{HNCO}: \mathrm{CO}$ ratios found in this and previous work. Findings from this work (see Sect. 3.1 and 3.2) suggest that none of the aftertreatment systems deployed on our diesel engine affected $\mathrm{HNCO}$ emissions but the DOC dramatically reduced $\mathrm{CO}$ emissions (factor of $\sim 30$ at $50 \%$ load for the engine described herein). In other words, for the same engine we anticipate that the presence of a DOC will increase $\mathrm{HNCO}: \mathrm{CO}$ ratios by a factor of 30, assuming that the HNCO emissions do not change with the DOC. Hence, we need to be careful about how we calculate the $\mathrm{HNCO}$ : $\mathrm{CO}$ ratio and also how the $\mathrm{HNCO}$ : $\mathrm{CO}$ ratio is applied to determine primary emissions of HNCO. Since we are modeling an episode prior to when diesel engines were required to have a DOC, we have only used non-DOC data to calculate low and high estimates for $\mathrm{HNCO}$ : $\mathrm{CO}$ ratios. Based on this work, and that of Link et al. (2016), Heeb and coworkers (Heeb et al., 2011, 2012), and Wentzell et al. (2013), we loosely calculated a lower bound $\mathrm{HNCO}: \mathrm{CO}$ ratio of $\sim 0.001$ that reflected diesel engine operation at lower engine loads and a higher $\mathrm{HNCO}: \mathrm{CO}$ ratio of $\sim 0.01$ that reflected diesel engine operation at higher engine loads; the $\mathrm{HNCO}$ : $\mathrm{CO}$ data from all sources are tabu- 
Table 1. Emissions and emission ratios for gasoline, diesel, and biomass burning sources for the state of California for an average summer day in 2005 .

\begin{tabular}{|c|c|c|c|c|}
\hline Source & $\begin{array}{r}\text { CO emissions } \\
\left(\text { tons day }^{-1}\right)\end{array}$ & HNCO : CO & $\begin{array}{r}\mathrm{HNCO} \\
\text { (tons day }^{-1} \text { ) }\end{array}$ & $\begin{array}{r}\text { HNCO precursor } \\
\quad\left(\text { tons day }^{-1}\right)\end{array}$ \\
\hline Gasoline & 8195 & $0.000036^{\mathrm{a}}$ & 0.29 & 0 \\
\hline Diesel (low) based on idle data & 447 & $0.001^{\mathrm{b}}$ & 0.45 & 2.21 \\
\hline Diesel (high) based on load data & 447 & $0.01^{\mathrm{b}}$ & 4.47 & 9.83 \\
\hline Biomass burning & 164 & $0.001^{\mathrm{c}}$ & 0.16 & 0 \\
\hline
\end{tabular}

${ }^{a}$ Brady et al. (2014). ${ }^{b}$ This work, Link et al. (2016), and Heeb et al. $(2011,2012) .{ }^{c}$ Roberts et al. (2011).

lated in Table $\mathrm{S} 1$ and the cumulative distribution function for the HNCO : CO data is show in Fig. S2.

The HNCO : $\mathrm{CO}$ ratio for the gasoline sources was determined as the ratio of the median $\mathrm{HNCO}$ to the median $\mathrm{CO}$ measured by Brady et al. (2014) for eight light-duty gasoline vehicles. The HNCO : CO ratio for biomass burning sources, which includes residential wood combustion, was based on an approximate fit to the laboratory and ambient data measured by Veres et al. (2010), Roberts et al. (2011), and Yokelson et al. (2013). We note that the previous study that simulated $\mathrm{HNCO}$ in a 3-D model developed global emissions of $\mathrm{HNCO}$ by using a source-specific ratio of $\mathrm{HNCO}$ with hydrogen cyanide (Young et al., 2012). The HNCO : CO ratios were then combined with source-specific, spatiotemporally resolved $\mathrm{CO}$ emissions to build source-resolved emissions for HNCO. HNCO from the three sources were tracked separately in the UCD/CIT model.

Link et al. (2016) observed strong photochemical production of $\mathrm{HNCO}$ from a diesel engine without any aftertreatment. This secondary HNCO source can be attributed to photooxidation of amides (e.g., formamide, acetamide) and potentially other reduced organic nitrogen compounds present in the diesel exhaust, though the full suite of precursors, their reaction mechanisms and their HNCO yields remains unknown. Hence, we make simplifying assumptions to parameterize photochemical production of HNCO in our CTM simulations. We assumed that diesel exhaust contains a single $\mathrm{HNCO}$ precursor $(X)$ that reacts with the hydroxyl radical $(\mathrm{OH})$ to form $\mathrm{HNCO}$, i.e., $X+\mathrm{OH} \rightarrow \mathrm{HNCO}$. Assuming that the emissions for $X$ scale with primary emissions of $\mathrm{HNCO}$, and $X$ and $\mathrm{OH}$ participate in a first-order reaction (i.e., $X=X_{0} e^{-k_{\mathrm{OH}}[\mathrm{OH}] \Delta t}$ ), the emissions for $X$ and its reaction rate with $\mathrm{OH}\left(k_{\mathrm{OH}}\right)$ can be determined from a fit to the experimental data from Link et al. (2016). Separate parameterizations for emissions of $X$ were developed for the two engine loads (idle and $50 \%$ load at rated speed) described in Link et al. (2016).

Fits and the parameters are shown in Fig. 1. The diesel and biodiesel data were nearly identical and hence data from both fuels were used to determine the engine-load-specific fits. The physical interpretation of the fit for idle conditions is that for $1 \mathrm{~kg}$ of fuel burned, $\sim 0.050 \pm 0.006 \mathrm{~g}$ of $\mathrm{HNCO}$ and $\sim 0.20 \pm 0.01 \mathrm{~g}$ of $X$ are emitted, with $X$ reacting with $\mathrm{OH}$ with a $k_{\mathrm{OH}}$ of $5.5 \pm 1.3 \times 10^{-12} \mathrm{~cm}^{3}$ molecules ${ }^{-1} \mathrm{~s}^{-1}$ to form HNCO. The fit values for the precursor scaling with respect to the primary emissions of $\mathrm{HNCO}$, i.e., $4.9 \pm 0.3$ at idle conditions and $2.2 \pm 0.2$ at $50 \%$ load conditions are 2.9 and 6.4 times lower and the fit $k_{\mathrm{OH}}$ value is approximately 2 times higher than that calculated by Roberts et al. (2014) from ambient observations (precursor scaling of 14.1 and $k_{\mathrm{OH}}$ of $2.33 \times 10^{-12} \mathrm{~cm}^{3}$ molecules ${ }^{-1} \mathrm{~s}^{-1}$ ). We note that our precursor scaling and $k_{\mathrm{OH}}$ fits are not unique and that we could produce a higher (or lower) precursor scaling and a corresponding lower (or higher) $k_{\mathrm{OH}}$ pair that would fit the data equally well and possibly align better with the fits from Roberts et al. (2014). Our fit value of $k_{\mathrm{OH}}$ compares quite well with that calculated by Borduas et al. (2014) for formamide $\left(4.44 \pm 0.46 \times 10^{-12} \mathrm{~cm}^{3}\right.$ molecules $\left.{ }^{-1} \mathrm{~s}^{-1}\right)$; Borduas et al. (2014) observed HNCO production from $\mathrm{OH}$ oxidation of formamide. Spatiotemporally resolved precursor emissions were developed for diesel sources by multiplying the primary HNCO emissions developed in the previous section by the scaling (i.e., 4.9 and 2.2) determined through the fits. The reaction chemistry to form secondary HNCO was added to SAPRC-11. We do not consider HNCO precursors for gasoline and biomass burning sources.

Roberts et al. (2011) have argued that the gas-phase reaction of $\mathrm{HNCO}$ with $\mathrm{OH}$, heterogeneous reaction of $\mathrm{HNCO}$ on an aerosol surface, and photolysis of HNCO are too slow to be relevant in the atmosphere and claimed that the only relevant loss mechanism for HNCO was dry and wet deposition. Young et al. (2012) investigated the influence of irreversible uptake of HNCO by clouds in a global model and found that this loss mechanism competed with dry deposition only when the cloud $p H$ was 6 or higher. In a followup study, Barth et al. (2013) used a detailed box model to suggest that the cloud uptake of HNCO was not irreversible (i.e., HNCO could be released into the gas phase after the cloud evaporated) although HNCO concentrations could be significantly depleted if air parcels containing HNCO encountered low-level cumulus clouds. Barth et al. (2013) have also suggested that HNCO could be taken up by aqueous aerosols that might serve as a sink. In this work, we only modeled dry deposition of HNCO as a loss mechanism, ignored all 


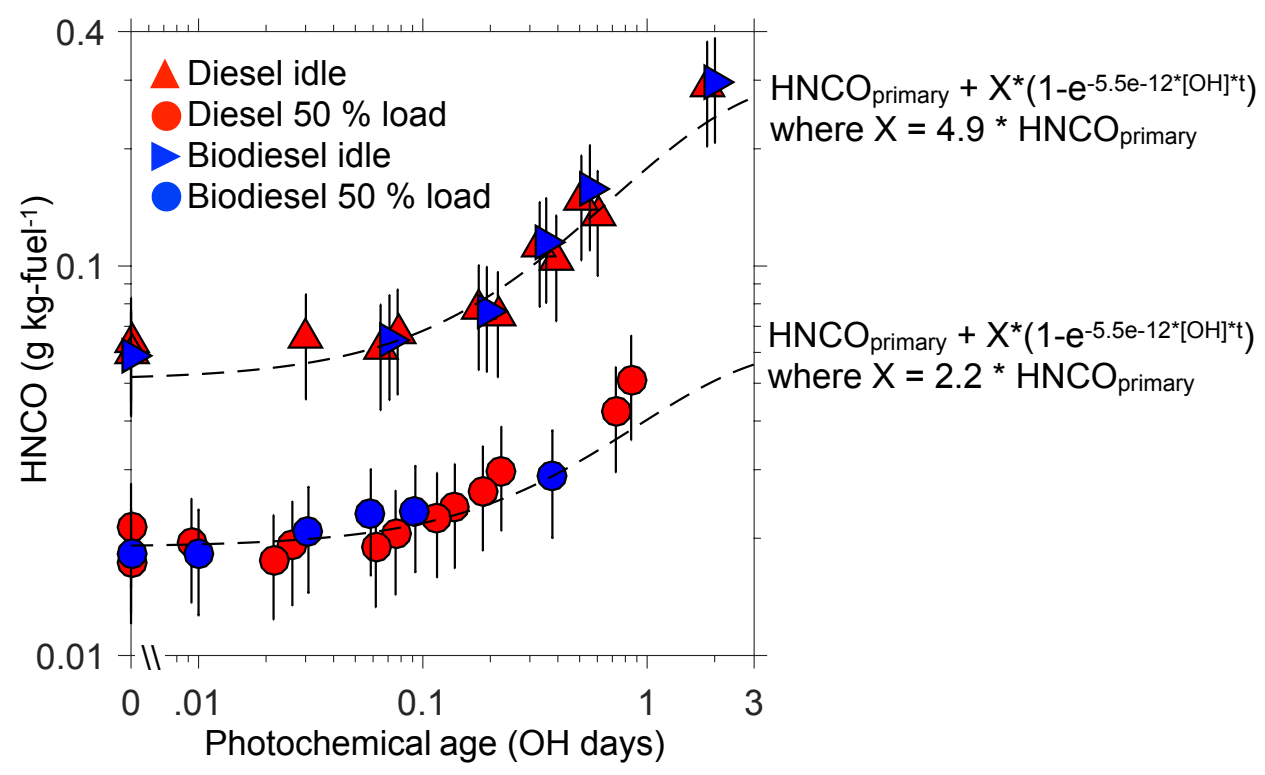

Figure 1. Emission/production factors for HNCO as a function of photochemical age from Link et al. (2016). The fits, which parameterize the emissions of the $\mathrm{HNCO}$ precursor and the reaction rate constant with $\mathrm{OH}$, have been performed in this work. The photochemical age is calculated assuming an $\mathrm{OH}$ concentration of $1.5 \times 10^{6}$ molecules $\mathrm{cm}^{-3}$.

other processes, and consequently provided an upper bound on our HNCO estimates. The dry deposition for HNCO was modeled assuming equivalence to nitric acid. We chose nitric acid since, like HNCO, nitric acid is extremely soluble in water at neutral $\mathrm{pH}$. The HNCO precursor $(X)$ was modeled as NO to determine its dry deposition.

\section{Results and discussion}

\section{1 $\mathrm{NO}_{x}$ and HNCO emission factors}

In Fig. 2, we plot emission factors for $\mathrm{NO}_{x}$ and $\mathrm{HNCO}$ as a function of the $\mathrm{NH}_{3}$ injection rates for all the experiments performed during our study. $\mathrm{NH}_{3}$ injection rates were calculated by assuming that all of the urea thermally decomposed into $\mathrm{NH}_{3}$. As expected, we saw a near-exponential decrease in $\mathrm{NO}_{x}$ emissions with a linear increase in $\mathrm{NH}_{3}$ injection. Within the calculated range of stoichiometric doses for $\mathrm{NH}_{3}, \mathrm{NO}_{x}$ emissions for most engine load-fuel combinations tested in this study were reduced by more than $90 \%$; stoichiometric doses of $\mathrm{NH}_{3}$ were calculated by assuming all of the $\mathrm{NO}_{x}$ was either $\mathrm{NO}$ or $\mathrm{NO}_{2}$ and followed reactions $\mathrm{R} 4$ and R5, respectively. The only exceptions were the idle-like load experiments (2400 RPM and $11 \mathrm{~kW})$, where we could not inject more $\mathrm{NH}_{3}\left(\gtrsim 0.012 \mathrm{~g} \mathrm{~s}^{-1}\right)$ since higher injections lowered the catalyst temperatures to values below those required for normal functioning of the $\operatorname{SCR}\left(<200^{\circ} \mathrm{C}\right)$. We also found that the $\mathrm{NO}_{x}$ emissions continued to decrease beyond stoichiometric injections of $\mathrm{NH}_{3}$. This allowed the SCRequipped diesel engine to meet and exceed the most recent
EPA Tier 4 emission standard of $\sim 1.6 \mathrm{~g}$ of $\mathrm{NO}_{x} \mathrm{~kg}$ fuel $^{-1}$ (or $0.4 \mathrm{~g}$ of $\mathrm{NO}_{x} \mathrm{~kW} \mathrm{~h}^{-1}$ ).

Similar to earlier work (Wentzell et al., 2013; Heeb et al., 2012, 2011; Suarez-Bertoa and Astorga, 2016), we observed $\mathrm{HNCO}$ when no $\mathrm{NH}_{3}$ was injected, implying that the $\mathrm{HNCO}$ was produced either in the engine cylinder or in the aftertreatment devices upstream of the SCR (DOC + DPF). For six of the seven experiments performed with diesel fuel, HNCO emissions were reduced by $5-40 \%$ with increasing $\mathrm{NH}_{3}$ injections. For one of the diesel experiments and both the biodiesel experiments in which the measured emission factors (and measured concentrations) for $\mathrm{HNCO}$ were the lowest, $\mathrm{HNCO}$ emissions increased by $30-125 \%$ as the $\mathrm{NH}_{3}$ injection was increased. In summary, it is unlikely that SCR-equipped engines running on diesel fuel are a source of $\mathrm{HNCO}$ even when the $\mathrm{NH}_{3}$ injection exceeds stoichiometric rates. It is possible that the use of biodiesel reduces primary emissions of $\mathrm{HNCO}$ and that the HNCO enhancements in these experiments reflect slight contributions from the SCR chemistry that are undetectable during most of the diesel experiments. The HNCO response on SCR systems when using biodiesel needs to be explored in future work.

\subsection{Comparison with earlier work}

Very few studies have investigated $\mathrm{HNCO}$ emissions from diesel engines and, before this work, only four studies have examined HNCO emissions from an SCR-equipped diesel engine. In Fig. 3, we compare HNCO emission factors for diesel fuel with all earlier work involving diesel engines: 


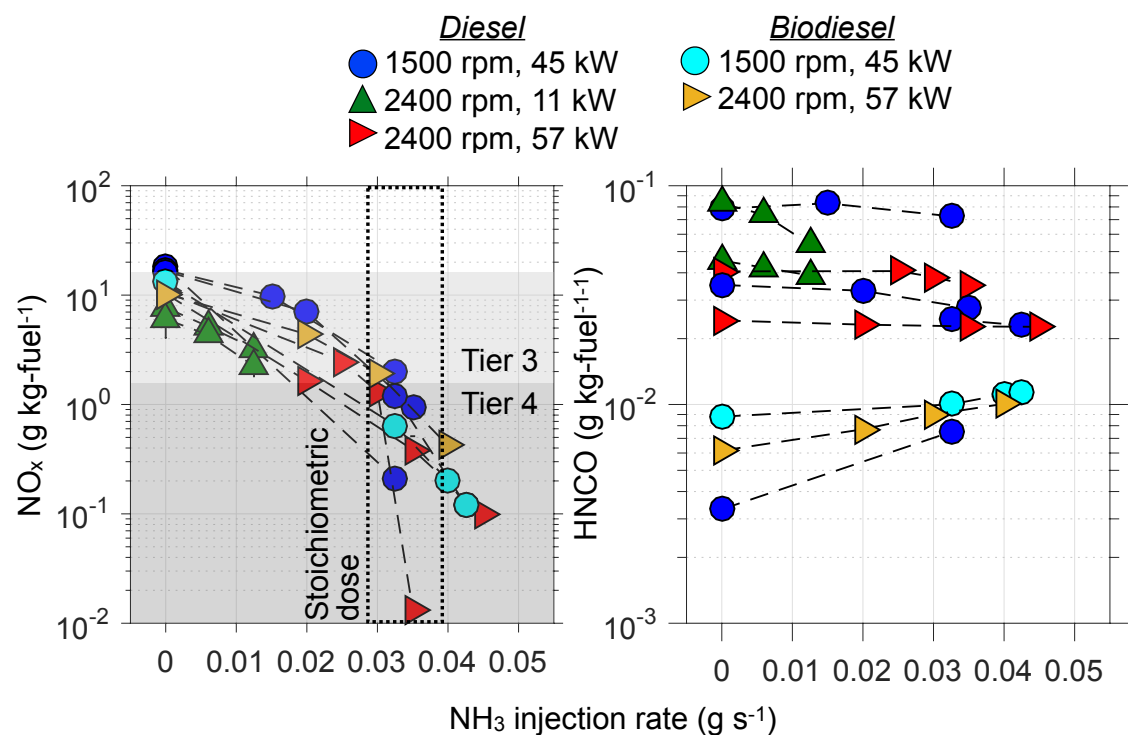

Figure 2. Emission factors for (a) $\mathrm{NO}_{x}\left(\mathrm{NO}+\mathrm{NO}_{2}\right)$ and (b) $\mathrm{HNCO}$ with varying $\mathrm{NH}_{3}$ injection rates for all the experiments performed in this work. The $\mathrm{NH}_{3}$ injection rates are calculated assuming each urea molecule produces two $\mathrm{NH}_{3}$ molecules.

Link et al. (2016), Wentzell et al. (2013), Heeb et al. (2011, 2012), and Suarez-Bertoa and Astorga (2016). We also compare our results to the average HNCO emissions from eight light-duty gasoline vehicles measured by Brady et al. (2014). For this work, the mean and the standard errors were calculated using the $\mathrm{HNCO}$ data across all $\mathrm{NH}_{3}$ injection rates. The HNCO emission factors across these six studies spanned nearly 3 orders of magnitude and, while providing some insight, highlight the uncertainty in both the emissions and the measurements of HNCO.

There are several interesting findings of note. First, the emission factors for HNCO from this work were nearly identical to those measured by Link et al. (2016). Since both studies were performed on the same engine and used a similar CIMS instrument, the HNCO was mostly likely produced in the engine cylinder and was unaltered by the DOC and DPF. Second, primary emissions of $\mathrm{HNCO}$ and its precursors based on the work of Link et al. (2016) were deemed plausible when compared against emissions of total unburned hydrocarbons; i.e., HNCO and its precursor at idle conditions were less than 0.2 and $1 \%$ of the total hydrocarbon emissions while $\mathrm{HNCO}$ and its precursor at $50 \%$ load conditions were less than 0.4 and $0.9 \%$ of the total hydrocarbon emissions. Third, the emission factors for HNCO from the engine used in this work (with or without the aftertreatment devices) were much higher (factor of 10-100) than those measured by Wentzell et al. (2013). Wentzell et al. (2013) used a CIMS instrument similar to that used in this study and therefore the differences could not be attributed to the instrumentation. Link et al. (2016) suggested that the large differences between their study and the Wentzell et al. (2013) study could reflect the variability found in emissions between non- and on-road diesel engines and steady and transient drive cycles. However, when compared using the HNCO : $\mathrm{CO}$ ratio, there was much less variability in the ratio between this work and two of the drive cycles examined by Wentzell et al. (2013) (see Table S1), which could suggest that our non-road engine, on account of being larger than the Wentzell et al. (2013) engine, simply produced more $\mathrm{HNCO}$ and more $\mathrm{CO}$ but yielded the same HNCO : CO ratio. This observation led us to assume (in Sect. 3.2) equivalence between non-road and onroad diesel engines as well as to develop emission inventories for $\mathrm{HNCO}$ based on the $\mathrm{HNCO}$ : $\mathrm{CO}$ ratio rather than through the use of emission factors. To test our findings and assumptions, we recommend that future studies focus on testing a diverse suite of diesel engine sizes under a wide range of steady and transient engine loads.

Fourth, the emission factors for HNCO from this study (31-56 mg kg fuel ${ }^{-1}$ ) compared reasonably well with those from an SCR-equipped diesel engine tested by Heeb and coworkers (Heeb et al., 2011, 2012) (29-32 $\mathrm{mg} \mathrm{kg} \mathrm{fuel}^{-1}$ ) but were slightly higher than the two SCR-equipped diesel vehicles tested by Suarez-Bertoa and Astorga (2016) (1.3$9.7 \mathrm{mg} \mathrm{kg} \mathrm{fuel}^{-1}$ ). However, in sharp contrast to our findings from Fig. 2, Heeb and coworkers (Heeb et al., 2011, 2012) saw dramatically reduced (factor of 10) HNCO emissions without the SCR and suggested that the SCR was a source of HNCO. Heeb and coworkers (Heeb et al., 2011, 2012) employed an offline technique to measure HNCO (liquid-phase sample collection followed by hydrolysis of $\mathrm{HNCO}$ to $\mathrm{NH}_{3}$ and measurement of $\mathrm{NH}_{3}$ ) and it is possible that differences in the HNCO emission factors reflect a change in the sensitivity of the technique to changes in $\mathrm{NH}_{3}$ concentrations in the tailpipe during SCR system operation. Suarez-Bertoa and 


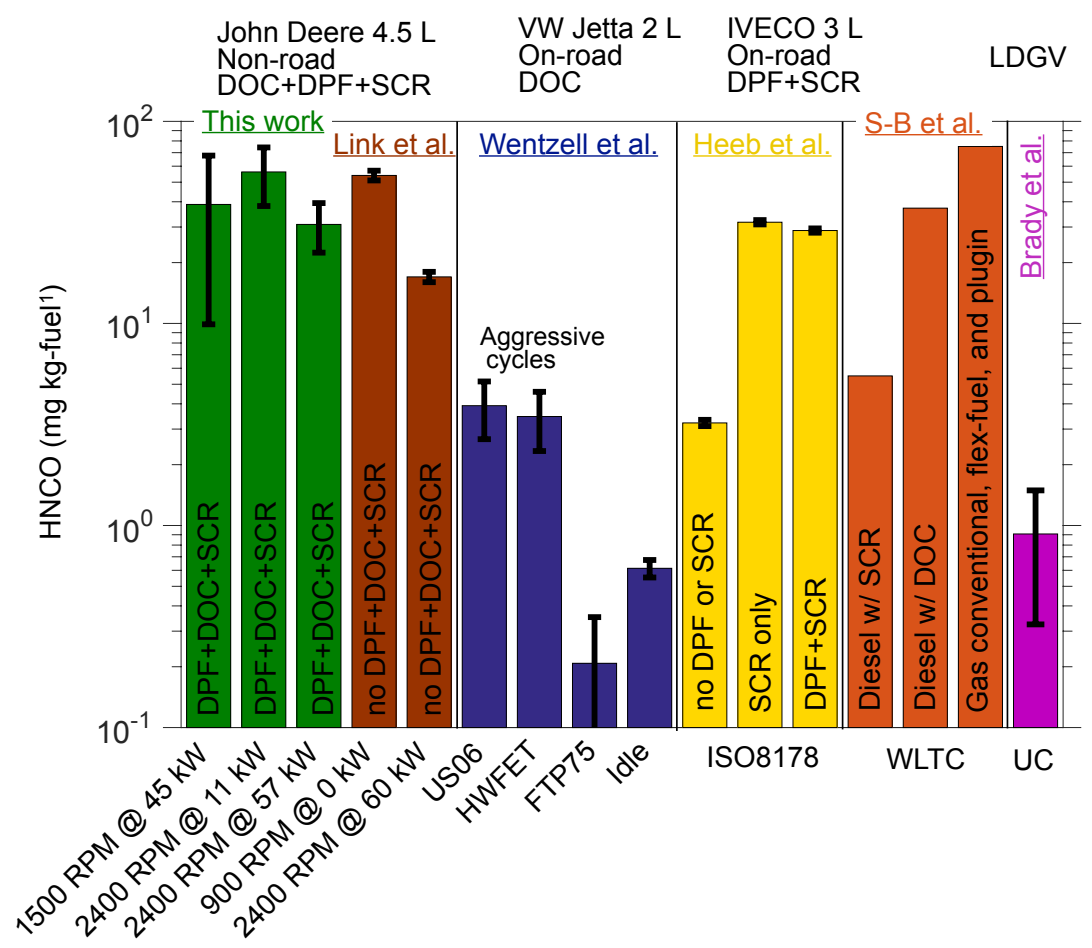

Figure 3. Emission factors for HNCO from this work compared to literature data. US06, HWFET, FTP75, ISO8178, WLTC, and UC are vehicle/engine drive cycles. S-B et al. refers to the Suarez-Bertoa and Astorga (2016) study.

Astorga (2016), in contrast to Heeb and coworkers (Heeb et al., 2011, 2012), found that the HNCO emission factors were lower for the two SCR-equipped vehicles than the non-SCR vehicle equipped with a DOC.

Finally, the emissions of HNCO on a fuel-burned basis from this work and Link et al. (2016) were more than an order of magnitude larger than the average HNCO emissions from the suite of light-duty gasoline vehicles tested by Brady et al. (2014) but similar to those measured by Suarez-Bertoa and Astorga (2016) for a range of light-duty gasoline vehicles. Suarez-Bertoa and Astorga (2016) have argued that their emission factors for $\mathrm{HNCO}$ were higher than those measured by Brady et al. (2014) because of differences in sampling tailpipe versus diluted emissions. Assuming the Brady et al. (2014) data are more atmospherically relevant, diesel engines, regardless of their use of aftertreatment devices, might be a much larger source of HNCO than catalytic-converter-equipped gasoline engines despite higher gasoline consumption in the United States compared to diesel $(\sim 3: 1)$.

\subsection{Chemical transport model results}

Predictions of 14-day averaged, ground-level concentrations of HNCO from the CTM simulations are mapped for the state of California in Fig. 4a-b. The low and high results are from two simulations that used two different primary emissions and photochemical production parameterizations for diesel engines (refer to Table 1 for details) and capture the uncertainty in modeling HNCO contributions from diesel-powered sources. Inland concentrations of HNCO between the low and high simulations varied significantly but never exceeded $110 \mathrm{pptv}$ and were at least an order of magnitude lower than the $1 \mathrm{ppbv}$ level proposed by Roberts et al. (2011). Roberts et al. (2011) argued that a 1 ppbv $\mathrm{HNCO}$ concentration would translate to a $100 \mu \mathrm{M}$ aqueous HNCO concentration, which would be sufficient to result in carbamylation reactions that have been linked to adverse health outcomes. The highest concentrations of $\mathrm{HNCO}$ were found in Los Angeles (low estimate $=20.1 \mathrm{pptv}$; high estimate $=107 \mathrm{pptv}$ ) located in SoCAB; SoCAB is home to 17 million people and consistently the most polluted in the United States for ozone and particulate matter (American Lung Association, 2016). HNCO concentrations from the high simulation in four other locations (Riverside, Fresno, Bakersfield, and Sacramento), where ozone and particulate matter concentrations are amongst the worst in the country, varied between 23 and 66 pptv.

We individually tracked the source/process-level contributions of $\mathrm{HNCO}$ in the CTM simulations and found that diesel use was the dominant source of HNCO in SoCAB. Based on the low and high simulations, diesel sources accounted for $55-92 \%$ while gasoline sources accounted for $8-41 \%$ of the HNCO in SoCAB, with a very small contribution (1$4 \%$ ) from biomass burning sources. The signature of a larger 
(a) HNCO (low) (pptv)

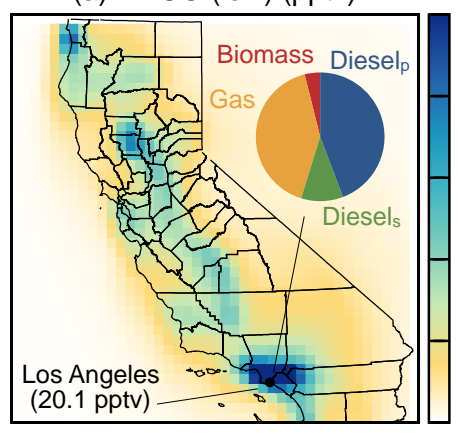

(b) HNCO (high) (pptv)

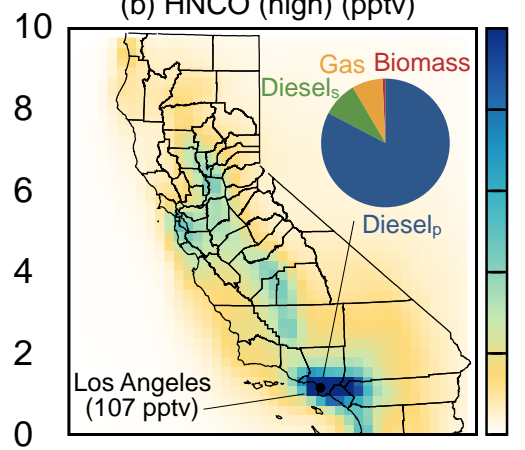

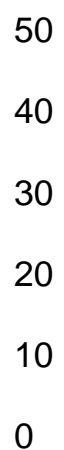

(c) Pasadena, CA

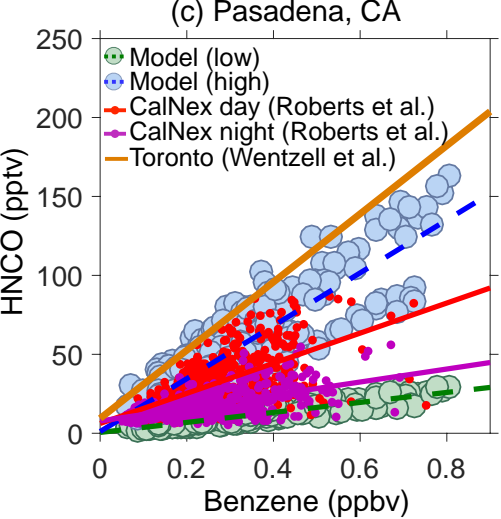

Figure 4. (a) Low and (b) high estimates of the 14-day averaged ground-level concentrations of HNCO from the $24 \mathrm{~km}$ simulations. The low and high estimates used two different primary emissions and photochemical production parameterizations for diesel engines (see Table 1). The color scales in panels (a) and (b) have been truncated at 10 and $50 \mathrm{pptv}$, respectively, to visualize the statewide variability in HNCO concentrations. We note that in both the panels, the HNCO concentrations in the Los Angeles region exceed the concentrations captured on the color scale. (c) 14-day averaged concentrations of HNCO regressed against benzene over the South Coast Air Basin from the $8 \mathrm{~km}$ simulations; also includes observations from Wentzell et al. (2013) for Toronto, 2012, and from Roberts et al. (2014) and Borbon et al. (2013) for Pasadena, 2010, during CalNex.

contribution of HNCO from biomass burning sources can be seen in Fig. 4a in more remote locations of California, e.g., northwest corner of California, north of Sacramento. Despite the strong photochemical production observed by Link et al. (2016) in laboratory experiments, secondary production of HNCO from precursors in diesel exhaust only accounted for $9-11 \%$ of the total HNCO. The most likely explanation for this small contribution was that the in-basin exposure of $\mathrm{HNCO}$ precursors to $\mathrm{OH}$ radicals was too small to produce a lot of secondary HNCO. In fact, the slow secondary production of $\mathrm{HNCO}$ can be visualized in Fig. 1, where significant enhancements in $\mathrm{HNCO}$ were only observed after $\sim 5 \mathrm{~h}$ of photochemical processing.

Furthermore, we investigated the sensitivity of model predictions to dry deposition by using $\mathrm{NO}$ as the surrogate to model dry deposition of HNCO; NO has a much slower dry deposition lifetime $(\sim$ weeks $)$ than nitric acid $(\sim \mathrm{h})$ and the use of $\mathrm{NO}$ as a surrogate was expected to cause $\mathrm{HNCO}$ concentrations to increase. Model predictions suggested that HNCO concentrations increased by $\sim 50 \%$ in urban areas and by a factor of 2 to 5 in rural/remote regions. This suggests that using nitric acid to model the dry deposition of HNCO could underpredict urban concentrations of HNCO by as much as $50 \%$. It is also worth noting that an order of magnitude change in the dry deposition lifetime only resulted in a $50 \%$ change in concentration, suggesting that dispersion, rather than deposition, plays an important role in controlling the urban HNCO concentrations.

\subsection{Model evaluation}

To evaluate the HNCO predictions from our CTM simulations, we compared model predictions from the $8 \mathrm{~km}$ simu- lation to two datasets of HNCO measurements in urban areas: (i) observations reported by Roberts et al. (2014) at the Pasadena ground site during the California Research at the Nexus of Air Quality and Climate Change (CalNex) study in May-June 2010 and (ii) observations reported by Wentzell et al. (2013) in Toronto in September-October 2012. Since the model simulations were not for the same time period (in the case of CalNex) or the same location (in the case of Toronto), we present the comparisons in Fig. 4c by regressing concentrations of HNCO against those of benzene. We chose benzene because Roberts et al. (2014) had developed an emission ratios for $\mathrm{HNCO}$ with respect to benzene and Wentzell et al. (2013) had previously found ambient HNCO concentrations to vary linearly with benzene concentrations.

Model predictions from the low simulation seemed to agree with the nighttime observations of Roberts et al. (2014) and validate the primary parameterizations and deposition scheme used in the low simulation. Roberts et al. (2014) have argued that the diurnal differences in the observations imply a daytime photochemical source of HNCO, where in the mid-afternoon secondary processing accounts for $40 \%$ of the total HNCO. Hence, agreement between the model predictions from the high simulation and the daytime observations of Roberts et al. (2014) should not be construed as a validation of the inputs for that simulation since the high simulation predicts a small contribution $(\sim 10 \%)$ of HNCO from photochemical production. One interpretation of this modelmeasurement comparison is that the low-simulation model is missing HNCO precursors from gasoline and biomass burning sources that may lead to increases in daytime production of HNCO. In contrast to the comparison at Pasadena, the model predictions from the high simulation compared well 
with rush hour observations of primary HNCO by Wentzell et al. (2013), which could be seen as a validation of the primary parameterizations in the high simulation. As is clear, the model evaluation is severely limited because of lack of laboratory datasets that can help parameterize the emissions and chemistry of $\mathrm{HNCO}$ and lack of observational datasets that can help validate those parameterizations. Nonetheless, the range of $\mathrm{HNCO}$ concentrations predicted between the low and high simulations are bound by the two observational datasets and, hence, this work provides a reasonable set of parameterizations to model HNCO in CTMs.

\section{Summary and conclusions}

We performed laboratory experiments on an SCR-equipped modern day diesel engine to measure emissions of isocyanic acid as a function of varying urea injection rates, engine loads, and fuels. We found no evidence that the SCR or the other aftertreatment devices (diesel oxidation catalyst and diesel particle filter) were a source of tailpipe HNCO. We argue that the $\mathrm{HNCO}$ from diesel engines was likely produced inside the engine cylinder during fuel combustion. This finding is not completely new. Chemical kinetics models (Mansour et al., 2001), model systems with propane (Nelson and Haynes, 1994), and engine tests without aftertreatment devices (Heeb et al., 2011) have previously shown that HNCO (and other reduced nitrogen-containing compounds) can be produced during combustion in the presence of $\mathrm{NO}_{x}$. We note that the exhaust gas recirculation (EGR) system that adds $\mathrm{NO}_{x}$-containing exhaust to the engine to reduce cylinder temperature and consequently reduce $\mathrm{NO}_{x}$ production may actually enhance in-cylinder HNCO production from the increased homogenous availability of $\mathrm{NO}_{x}$; the engine employed in this work and most of those found in the United States on mobile sources have EGRs. EGRs as an enabler of in-cylinder HNCO production needs to be explored in future studies.

Amides such as formamide are known precursors of HNCO (Borduas et al., 2014) and might be part of amide emissions from various types of combustion sources that lead to atmospheric production of HNCO. Recent studies have noted that other forms of reduced organic nitrogen compounds can be oxidized to form HNCO, suggesting that molecules other than amides emitted from diesel exhaust may also be HNCO precursors (Borduas et al., 2016a, b). Fits to the data from Link et al. (2016) suggest that the emissions and the rate of photochemical production of $\mathrm{HNCO}$ attributed to diesel sources may not be sufficient to contribute significantly to ambient concentrations of HNCO in urban environments. These precursors, however, might be important in controlling HNCO concentrations in remote/rural environments but based on the results from this study might be deemed too low to be of any concern from a health perspective. Our CTM predictions suggest that the daily-averaged precursor concentrations in urban environments are large enough (50-250 pptv in Los Angeles; see Fig. S3 for precursor concentrations in California) to provide impetus for ambient studies to design and deploy instruments to measure these precursors. Finally, it is possible that sources other than diesel engines (e.g., gasoline engines, biomass burning, agricultural burning) also emit precursors of $\mathrm{HNCO}$ and hence need to be studied in the future both in terms of identifying and quantifying the precursors of $\mathrm{HNCO}$ and measuring their potential to form HNCO.

Using our experimentally determined emission factors, we used a CTM to simulate ground-level concentrations and source (gasoline, diesel, biomass burning) and process (primary, secondary) contributions to HNCO in California. The predicted HNCO concentrations in Southern California were roughly similar to those measured at Pasadena in 2010, Toronto in 2012, and La Jolla in 2012. A detailed comparison at Pasadena highlighted missing precursors/pathways for photochemical production of HNCO during the daytime. The comparisons also implied that diesel engines (and possibly gasoline engines) are large sources of HNCO in urban areas. In the simulations, daily-averaged $\mathrm{HNCO}$ concentrations never exceeded 110 pptv and were an order of magnitude below the 1 ppbv level that Roberts et al. (2014) have proposed could result in human health effects. If we assume that the HNCO-benzene regression from our work holds for other parts of the world, benzene concentrations exceeding $7 \mathrm{ppbv}$ would be associated with 1 ppbv levels of $\mathrm{HNCO}$; we expect benzene and HNCO to correlate only in source and/or urban regions and the regression may not be applicable for remote/rural locations since $\mathrm{HNCO}$ and benzene may have very different atmospheric lifetimes. We should note that the $1 \mathrm{ppbv}$ threshold is a rough estimate and we see a need for epidemiological and/or toxicological studies that would better inform that estimate. Emissions from biomass burning sources in the winter combined with a strong likelihood for temperature inversions could lead to higher HNCO concentrations in the winter and need to be explored using both measurements and air quality modeling.

Data availability. Summary data from the laboratory experiments and hourly- and daily-averaged data from the CTM simulations are archived at https://hdl.handle.net/10217/182733 (Jathar, 2017).

\section{The Supplement related to this article is available online at https://doi.org/10.5194/acp-17-8959-2017-supplement.}

Competing interests. The authors declare that they have no conflict of interest. 
Acknowledgements. We would like to thank Daniel Olsen for inputs on experimental design, Kirk Evans for technical support, and undergraduate researcher Liam Lewane for engine test support during the study. We would also like to thank DCL International Inc. for donating SCR catalysts for our study and Ricardo SuarezBertoa and Covadonga Astorga for sharing HNCO emissions data from their published study. Delphine K. Farmer acknowledges an Arnold and Mabel Beckman Young Investigator Award for funding the laboratory HNCO measurements.

Edited by: John Liggio

Reviewed by: two anonymous referees

\section{References}

American Lung Association: State of the Air, available at: http://www.lung.org/about-us/media/press-releases/ 2016-state-of-the-air.html, last access: 1 December 2016.

Alexeeff, G., Budroe, J., Collins, J., Dodge, D., Fowles, J., Faust, J., Lam, R., Lewis, D., Marty, M., and Mycroft, F.: Determination of noncancer chronic reference exposure levels, Office of Environmental Health Hazard Assessment, California Environmental Protection Agency, Sacramento, CA, USA, 2000.

Barth, M., Cochran, A., Fiddler, M., Roberts, J., and Bililign, S.: Numerical modeling of cloud chemistry effects on isocyanic acid (HNCO), J. Geophys. Res.-Atmos., 118, 8688-8701, 2013.

Borduas, N., da Silva, G., Murphy, J. G., and Abbatt, J. P.: Experimental and theoretical understanding of the gas phase oxidation of atmospheric amides with $\mathrm{OH}$ radicals: kinetics, products, and mechanisms, J. Phys. Chem. A, 119, 4298-4308, 2014.

Borduas, N., Abbatt, J. P., Murphy, J. G., So, S., and da Silva, G.: Gas-Phase Mechanisms of the Reactions of Reduced Organic Nitrogen Compounds with OH Radicals, Environ. Sci. Technol., 50, 11723-11734, 2016a.

Borduas, N., Murphy, J. G., Wang, C., da Silva, G., and Abbatt, J. P.: Gas phase oxidation of nicotine by $\mathrm{OH}$ radicals: Kinetics, mechanisms, and formation of HNCO, Environ. Sci. Technol. Lett., 3, 327-331, 2016b.

Brady, J. M., Crisp, T. A., Collier, S., Kuwayama, T., Forestieri, S. D., Perraud, V. r., Zhang, Q., Kleeman, M. J., Cappa, C. D., and Bertram, T. H.: Real-time emission factor measurements of isocyanic acid from light duty gasoline vehicles, Environ. Sci. Technol., 48, 11405-11412, 2014.

Broughton, E.: The Bhopal disaster and its aftermath: a review, Environ. Health, 4, 6, https://doi.org/10.1186/1476-069X-4-6, 2005.

Chandra, B. P. and Sinha, V.: Contribution of post-harvest agricultural paddy residue fires in the NW Indo-Gangetic Plain to ambient carcinogenic benzenoids, toxic isocyanic acid and carbon monoxide, Environ. Int., 88, 187-197, 2016.

Coggon, M. M., Veres, P. R., Yuan, B., Koss, A., Warneke, C., Gilman, J. B., Lerner, B. M., Peischl, J., Aikin, K. C., and Stockwell, C. E.: Emissions of nitrogen-containing organic compounds from the burning of herbaceous and arboraceous biomass: Fuel composition dependence and the variability of commonly used nitrile tracers, Geophys. Res. Lett., 43, 99039912, 2016.

Drenth, A. C., Olsen, D. B., Cabot, P. E., and Johnson, J. J.: Compression ignition engine performance and emission evaluation of industrial oilseed biofuel feedstocks camelina, carinata, and pennycress across three fuel pathways, Fuel, 136, 143-155, 2014.

Emmons, L. K., Walters, S., Hess, P. G., Lamarque, J.-F., Pfister, G. G., Fillmore, D., Granier, C., Guenther, A., Kinnison, D., Laepple, T., Orlando, J., Tie, X., Tyndall, G., Wiedinmyer, C., Baughcum, S. L., and Kloster, S.: Description and evaluation of the Model for Ozone and Related chemical Tracers, version 4 (MOZART-4), Geosci. Model Dev., 3, 43-67, https://doi.org/10.5194/gmd-3-43-2010, 2010.

Fullerton, D. G., Bruce, N., and Gordon, S. B.: Indoor air pollution from biomass fuel smoke is a major health concern in the developing world, T. Roy. Soc. Trop. Med. H., 102, 843-851, 2008.

Gordon, T. D., Presto, A. A., Nguyen, N. T., Robertson, W. H., Na, K., Sahay, K. N., Zhang, M., Maddox, C., Rieger, P., Chattopadhyay, S., Maldonado, H., Maricq, M. M., and Robinson, A. L.: Secondary organic aerosol production from diesel vehicle exhaust: impact of aftertreatment, fuel chemistry and driving cycle, Atmos. Chem. Phys., 14, 4643-4659, https://doi.org/10.5194/acp-14-4643-2014, 2014.

Guenther, A., Karl, T., Harley, P., Wiedinmyer, C., Palmer, P. I., and Geron, C.: Estimates of global terrestrial isoprene emissions using MEGAN (Model of Emissions of Gases and Aerosols from Nature), Atmos. Chem. Phys., 6, 3181-3210, https://doi.org/10.5194/acp-6-3181-2006, 2006.

Heeb, N. V., Zimmerli, Y., Czerwinski, J., Schmid, P., Zennegg, M., Haag, R., Seiler, C., Wichser, A., Ulrich, A., and Honegger, P.: Reactive nitrogen compounds (RNCs) in exhaust of advanced $\mathrm{PM}-\mathrm{NO}_{x}$ abatement technologies for future diesel applications, Atmos. Environ., 45, 3203-3209, 2011.

Heeb, N. V., Haag, R., Seiler, C., Schmid, P., Zennegg, M., Wichser, A., Ulrich, A., Honegger, P., Zeyer, K., and Emmenegger, L.: Effects of a combined diesel particle filter-DeNOx system (DPN) on reactive nitrogen compounds emissions: a parameter study, Environ. Sci. Technol., 46, 13317-13325, 2012.

Hildemann, L. M., Cass, G. R., and Markowski, G. R.: A dilution stack sampler for collection of organic aerosol emissions: design, characterization and field tests, Aerosol Sci. Tech., 10, 193-204, 1989.

Hu, J., Howard, C. J., Mitloehner, F., Green, P. G., and Kleeman, M. J.: Mobile source and livestock feed contributions to regional ozone formation in Central California, Environ. Sci. Technol., 46, 2781-2789, 2012.

Hu, J., Zhang, H., Ying, Q., Chen, S.-H., Vandenberghe, F., and Kleeman, M. J.: Long-term particulate matter modeling for health effect studies in California - Part 1: Model performance on temporal and spatial variations, Atmos. Chem. Phys., 15, 34453461, https://doi.org/10.5194/acp-15-3445-2015, 2015.

Jathar, S. H.: HNCO low and high simulations, available at: https: //hdl.handle.net/10217/182733, last access: 23 July 2017.

Jathar, S. H., Cappa, C. D., Wexler, A. S., Seinfeld, J. H., and Kleeman, M. J.: Multi-generational oxidation model to simulate secondary organic aerosol in a 3-D air quality model, Geosci. Model Dev., 8, 2553-2567, https://doi.org/10.5194/gmd-8-2553-2015, 2015.

Jathar, S. H., Mahmud, A., Barsanti, K. C., Asher, W. E., Pankow, J. F., and Kleeman, M. J.: Water uptake by organic aerosol and its influence on gas/particle partitioning of secondary organic aerosol in the United States, Atmos. Environ., 129, 142-154, 2016. 
Jathar, S. H., Friedman, B., Galang, A. A., Link, M. F., Brophy, P., Volckens, J., Eluri, S., and Farmer, D. K.: Linking Load, Fuel and Emission Controls to Photochemical Production of Secondary Organic Aerosol from a Diesel Engine, Environ. Sci. Technol., 51, 1377-1386, https://doi.org/10.1021/acs.est.6b04602, 2017.

Kleeman, M. J. and Cass, G. R.: A 3D Eulerian source-oriented model for an externally mixed aerosol, Environ. Sci. Technol., 35, 4834-4848, 2001.

Link, M., Friedman, B., Fulgham, R., Brophy, P., Galang, A., Jathar, S., Veres, P., Roberts, J., and Farmer, D.: Photochemical processing of diesel fuel emissions as a large secondary source of isocyanic acid (HNCO), Geophys. Res. Lett., 43, 4033-4041, 2016.

Lipsky, E. M. and Robinson, A. L.: Effects of dilution on fine particle mass and partitioning of semivolatile organics in diesel exhaust and wood smoke, Environ. Sci. Technol., 40, 155-162, 2006.

Mansour, C., Bounif, A., Aris, A., and Gaillard, F.: Gas-Diesel (dual-fuel) modeling in diesel engine environment, Int. J. Therm. Sci., 40, 409-424, 2001.

May, A. A., Nguyen, N. T., Presto, A. A., Gordon, T. D., Lipsky, E. M., Karve, M., Gutierrez, A., Robertson, W. H., Zhang, M., Chang, O., Chen, S., Cicero-Fernandez, P., Fuentes, M., ShiouMei, H., Ling, R., Long, J., Maddox, C., Massetti, J., McCauley, E., Na, K., Pang, Y., Rieger, P., Sax, T., Truong, T., Vo, T., Chattopadhyay, S., Maldonado, H., Maricq, M., and Robinson, A. L.: Gas- and particle-phase primary emissions from in-use, onroad gasoline and diesel vehicles, Atmos. Environ., 88, 247-260, https://doi.org/10.1016/j.atmosenv.2014.01.046, 2014.

Nelson, P. and Haynes, B.: Hydrocarbon- $\mathrm{NO}_{x}$ interactions at low temperatures - 1 . Conversion of $\mathrm{NO}$ to $\mathrm{NO}_{2}$ promoted by propane and the formation of $\mathrm{HNCO}$, Symposium (International) on Combustion, 25, 1003-1010, https://doi.org/10.1016/S00820784(06)80737-X, 1994.

Roberts, J. M., Veres, P. R., Cochran, A. K., Warneke, C., Burling, I. R., Yokelson, R. J., Lerner, B., Gilman, J. B., Kuster, W. C., and Fall, R.: Isocyanic acid in the atmosphere and its possible link to smoke-related health effects, P. Natl. Acad. Sci. USA, 108, 8966-8971, 2011.

Roberts, J. M., Veres, P. R., VandenBoer, T. C., Warneke, C., Graus, M., Williams, E. J., Lefer, B., Brock, C. A., Bahreini, R., Öztürk, F., Middlebrook, A. M., Wagner, N. L., Dubé, W. P., and de Gouw, J. A.: New insights into atmospheric sources and sinks of isocyanic acid, HNCO, from recent urban and regional observations, J. Geophys. Res.-Atmos., 119, 1060-1072, https://doi.org/10.1002/2013JD019931, 2014.

Scott, D. L., Wolfe, F., and Huizinga, T. W. J.: Rheumatoid Arthritis, Lancet, 376, 1094-1108, 2010.
Suarez-Bertoa, R. and Astorga, C.: Isocyanic acid and ammonia in vehicle emissions, Transportation Res. D Tr. E., 49, 259-270, 2016.

SWEA: Occupational Exposure Limit Values and Measures Against Air Contaminants, Swedish Work Environmental Authority, available at: https://www.av.se/globalassets/filer/publikationer/ foreskrifter/hygieniska-gransvarden-afs-2015-7.pdf (last access: 1 December 2016), 2005.

Veres, P., Roberts, J. M., Burling, I. R., Warneke, C., de Gouw, J., and Yokelson, R. J.: Measurements of gas-phase inorganic and organic acids from biomass fires by negative-ion proton-transfer chemical-ionization mass spectrometry, J. Geophys. Res.Atmos., 115, D23302, https://doi.org/10.1029/2010JD014033, 2010.

Wang, Z., Nicholls, S. J., Rodriguez, E. R., Kummu, O., Horkko, S., Barnard, J., Reynolds, W. F., Topol, E. J., DiDonato, J. A., and Hazen, S. L.: Protein carbamylation links inflammation, smoking, uremia and atherogenesis, Supplement, Nat. Med., 13, 1176-1184, https://doi.org/10.1038/nm1637, 2007.

Wentzell, J. J., Liggio, J., Li, S.-M., Vlasenko, A., Staebler, R., Lu, G., Poitras, M.-J. E., Chan, T., and Brook, J. R.: Measurements of gas phase acids in diesel exhaust: a relevant source of HNCO?, Environ. Sci. Technol., 47, 7663-7671, 2013.

Wiedinmyer, C., Akagi, S. K., Yokelson, R. J., Emmons, L. K., AlSaadi, J. A., Orlando, J. J., and Soja, A. J.: The Fire INventory from NCAR (FINN): a high resolution global model to estimate the emissions from open burning, Geosci. Model Dev., 4, 625641, https://doi.org/10.5194/gmd-4-625-2011, 2011.

Yokelson, R. J., Burling, I. R., Gilman, J. B., Warneke, C., Stockwell, C. E., de Gouw, J., Akagi, S. K., Urbanski, S. P., Veres, P., Roberts, J. M., Kuster, W. C., Reardon, J., Griffith, D. W. T., Johnson, T. J., Hosseini, S., Miller, J. W., Cocker III, D. R., Jung, H., and Weise, D. R.: Coupling field and laboratory measurements to estimate the emission factors of identified and unidentified trace gases for prescribed fires, Atmos. Chem. Phys., 13, 89-116, https://doi.org/10.5194/acp-13-89-2013, 2013.

Young, P., Emmons, L. K., Roberts, J. M., Lamarque, J. F., Wiedinmyer, C., Veres, P., and VandenBoer, T. C.: Isocyanic acid in a global chemistry transport model: Tropospheric distribution, budget, and identification of regions with potential health impacts, J. Geophys. Res.-Atmos., 117, D10308, https://doi.org/10.1029/2011JD017393, 2012.

Zhao, R., Lee, A., Wentzell, J., Mcdonald, A., Toom-Sauntry, D., Leaitch, W., Modini, R., Corrigan, A., Russell, L., and Noone, K.: Cloud partitioning of isocyanic acid (HNCO) and evidence of secondary source of HNCO in ambient air, Geophys. Res. Lett., 41, 6962-6969, 2014. 